Revista de Estudios Histórico-Jurídicos

[Sección historia del derecho canónico]

XLI (Valparaíso, Chile, 2019)

[pp. 141- 153]

\title{
LA RUPTURA DEL VÍNCULO MATRIMONIAL POR DISPARIDAD DE CULTO EN EL IUS COMMUNE BAJOMEDIEVAL
}

[Marital Breakdown due to Disparity of Worship in The Ius Commune in the Late Middle Ages ]

\author{
Alejandro Morin* \\ Conicet. Universidad de Buenos Aires \\ Universidad Nacional de Córdoba, Argentina
}

\begin{abstract}
RESUMEN
Hablar de ruptura del vínculo matrimonial por disparidad de cultos en el derecho bajomedieval parece una cuestión que se cierra en sí misma desde el momento en que tal circunstancia constituía un impedimento que proscribía el matrimonio entre cristianos e infieles. Sin embargo, juristas y tribunales debieron enfrentar situaciones concretas en las que los cónyuges respondían a diferentes le ye s, como en el caso de matrimonios de infieles en los que uno de los esposos se convierte al cristianismo o el caso inverso en el que, en un matrimonio cristiano, uno de los cónyuges apostata o cae en la herejía. El desarrollo jurídico planteado para responder a estas cuestiones revela que la construcción del matrimonio cristiano desde el s. XII con sus radicales características (indisolubilidad, monogamia, exogamia) prima sobre otros intereses, como puede ser la persecución de los herejes.
\end{abstract}

\section{Palabras Clave}

Derecho medieval - ruptura de vínculo matrimonial - impedimento disparis cultus.

\section{AbStract}

Speaking about dissolution of marital bond due to disparity of cult in medieval law seems to be a dead-end issue since such circumstance constituted an impediment that forbade marriage between Christians and Infidels from the outset. However, jurists and courts had to face specific situations in which the spouses belonged to different laws, such as in the case of marriages of Infidels in which one of the spouses converted to Christianity or the reverse case in which, in a marriage of Christians, one of the spouses apostatized or fell into heresy. The legal development carried out to answer these questions reveals that the construction of Christian marriage from the 12th century with its radical characteristics (indissolubility, monogamy, exogamy) predominates over other interests, such as the persecution of heretics.

\section{KEYWORDS}

Medieval Law - dissolution of marital bond - disparis cultus impediment.

ReCibido el 17 de noviembre de 2018 y ACEPTADO el 20 de marzo de 2019

\footnotetext{
*Investigador Adjunto CONICET, Saavedra $155^{\circ}$, Buenos Aires, alemorin1967@gmail.
} com 
Tras una evolución histórica particular, la sociedad cristiana medieval construyó un tipo de unión matrimonial que, como dicen Alain Guerreau y Anita Guerreau-Jalabert, se diferencia radicalmente de las formas previas (del derecho romano), contemporáneas (las del mundo islámico) y posteriores (el matrimonio civil de la sociedad producto de las revoluciones liberales) ${ }^{1}$. En efecto, el matrimonio cristiano viene definido por unas regulaciones que la legislación canónica intentará llevar hasta sus últimas consecuencias: una estricta monogamia, una clara tendencia a la hiperexogamia y una indisolubilidad casi total. Estas peculiaridades (que están en la base de innumerables conflictos entre la aristocracia laica y la eclesiástica entre los siglos XI y XIII) ${ }^{2}$ se combinan, además, con la dualidad de dos sistemas de parentesco, por cuanto la sociedad medieval ha generado a la par un sistema de parentesco llamado e s p i r i t u a l que replica y subordina

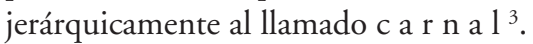

En un mundo en el que las referencias bíblicas tienen tanta o más fuerza que la ley positiva, el matrimonio se presenta como una institución de fundación divina de tiempos prelapsarios (según el relato de Gen. 2, 24) que hace de los esposos una caro, u n a c a r n e. A su vez, el Nuevo Testamento plantea desde el propio discurso del Salvador la idea de la indisolubilidad con la prohibición de separar el hombre lo que Dios ha unido (Mat. 19, 6, Mar. 10, 9, Luc. 16, 18). Salvo por la espinosa posibilidad de divorcio por fornicación (vale decir, por ruptura de la unitas carnis ${ }^{4}$ ) que Mat. 19, 9 parecía haber planteado y que será retomada luego en el área protestante ${ }^{5}$ el carácter indisoluble del lazo matrimonial era en principio incuestionable (independientemente de la posibilidad de un divortium quoad torum, la separación física de los esposos). Dicha indisolubilidad era pensada hasta

${ }^{1}$ Guerreau, Alain El feudalismo. Un horizonte teórico (trad. cast. Barcelona, Crítica, 1984); Guerreau-Jalabert, Anita, El sistema de parentesco medieval. Sus formas (real lespiritual) y su dependencia con respecto a la organización del espacio, en PASTOR, Reyna (comp.), Relaciones de poder, de producción y parentesco en la Edad Media y Moderna. Aproximación a su estudio (Madrid, Consejo Superior de Investigaciones Científicas, 1990).

${ }^{2}$ Duby, Georges, Le chevalier, la femme et le pretre. Le mariage dans la France féodale (Paris, Hachette, 1981).

${ }^{3}$ Guerreau-Jalabert, Anita, cit. (n. 1); Morsel, Joseph, L'Histoire (du Moyen Âge) est un sport de combat (Paris, Lamop-Paris I, 2007), pp. 128-135.

${ }^{4}$ Tal como lo expresa Rolando en su comentario a C. 32, q. 1, c. 2: "Sola fornicatio est, quae uxoris vincit affectum, i.e. quae facit licitum uxorem dimittere. Dico licitum, immo etiam necessarium, et hoc est: immo cum illa unam carnem in duas diviserit", Rolando, Die Summa Magistri Rolandi nachmals Papstes Alexander III. (Thaner F. [ed.], Innsbruck, Verlag der Wagnerischen Universitaets-Buchhandlung, 1874).

${ }^{5}$ La cláusula de fornicationis exceptio de Mat. 19, 9 es un punto de debate en la canonística $\mathrm{y}$, aunque la exégesis suela minimizar este pasaje, lo cierto es que generará discusiones y allí se apoyarán las iglesias protestantes para justificar la posibilidad de divorcio. Cfr. GAUDEMET, Jean, Le Mariage en Occident. Les moeurs et le droit (Paris, Les Editions du Cerf, 1987), pp. 46 y 128-129. También Owen Hughes, Diane Il matrimonio nell'Italia medievale, en KLAPISCHZuber, Christiane \& De Giorgio, Michela Storia del matrimonio (Bari, Laterza, 1996), p. 46, y Dillard, Heath, Daughters of the Reconquest. Women in Castilian Town Society, 1100-1300 (Cambridge, University Press, 1984), p. 205. 
la muerte, o quizá incluso más allá, si seguimos el hilo de las discusiones canónicas sobre el matrimonio de Lázaro en la hipótesis de una resucitación milagrosa ${ }^{6}$.

La indisolubilidad se deriva, por otra parte, de la propia naturaleza dual del matrimonio en la doctrina clásica de los canonistas, su doble carácter de contrato y sacramento. A finales del s. XII, tras un período de disputa entre dos posiciones identificadas por la historiografía como una postura c a n ó n i c a (que hacía de la unión sexual el factor constitutivo del casamiento) y otra t e o l ó g i c a (que, en cambio, hacía del consentimiento de los cónyuges el elemento determinante), se plantea la noción de un matrimonio por fases ${ }^{7}$. Una primera, incoativa, en la que este se presenta como un contrato, un encuentro de dos voluntades libres que expresan (en palabras de presente) su consenso para formar una sociedad: en estos términos, el matrimonio supone ya la unión del fiel con Dios a través de la fe y la caridad, un lazo, sin embargo, que puede romperse por el pecado o por la entrada en religión de los esposos. Mas es el ayuntamiento carnal el que perfecciona el matrimonio y representa la unión de Cristo y la Iglesia, indisoluble a partir de la unitas carnis de los cónyuges ${ }^{8}$. Esta combinación de consenso y sexualidad es lo que la historiografía llamó ví a $\mathrm{m}$ e d i a , aunque varios estudios recientes han puesto en cuestión la naturaleza de tal d i s p u t a entre una teoría coitalcanónica y otra consensual-teológica ${ }^{9}$. De todos modos, una vez que se imponga esta articulación, el matrimonio aparecerá como un engranaje de una eclesiología que no admitía rupturas y que significaba que, además de la prole y el remedio a la concupiscencia, el matrimonio/sacramento confería también la gracia ${ }^{10}$.

\section{EL CASO DE LOS NO BAUTIZADOS}

¿Qué ocurre con esta naturaleza sacramental del matrimonio cuando los cónyuges responden a distintas leyes, lo que hoy llamaríamos una diferencia de religiones? Se trata de una pregunta que abre una cuestión para, al parecer, cerrarla inmediatamente después, ya que para la legislación canónica la diferencia (que

${ }^{6}$ Vallejo, Jesús, Derecho como cultura. Equidady orden desde la óptica del “ius commune”, en De Dios, Salustiano et al. (coords.), Historia de la propiedad. patrimonio cultural, III: Encuentro interdisciplinar, Salamanca, 28 - 31 de mayo de 2002 (Madrid, Servicio de Estudios del Colegio de Registradores, 2003), pp. 56-59; MAdero, Marta, La loi de la chair. Le droit au corps du conjoint dans l'auvre des canonistes (XIIe-XVe siècles) (Paris, Publications de la Sorbonne, 2015), pp. 219-223.

${ }^{7}$ Brundage, James, La ley, el sexo y la sociedad cristiana en la Europa medieval (trad. cast., México, F.C.E. 2000), pp. 270-281.

${ }^{8}$ Dauvillier, Jean, Le mariage dans le droit classique de l'Église, depuis le Décret de Graden (1140) jusqu’à la mort de Clément V (1314) (Paris, Recueil Sirey, 1933), p. 79.

${ }^{9}$ Véase Reynolds, Philip L., The Regional Origins of Theories about Marital Consent and Consummation during the Twelfth Century, en KorPIOLA, Mia, Regional Variations in Matrimonial Law and Custom in Europe, 1150-1600 (Leiden: Brill, 2011), pp. 43-75; MADERO, Marta, cit. (n. 6), pp. 55-79; ÁlVAREZ DE LAS AstURIAS, Nicolás, La formación del vinculo matrimonial de Graciano a Alejandro III: ¡tan sólo una cuestión histórica?, en Ius Canonicum, 53 (2013), pp. 621-654.

${ }^{10}$ Mayal, Laurent "Duo erunt in carne una" and the Medieval Canonists, en Colli, Vincenzo y ConTe, Emanuele (eds.), Iuris Historia: Liber Amicorum Gero Dolezalek (Berkeley, The Robbins Collection, 2008), pp. 161-75. 
hoy llamamos) religiosa era un impedimento dirimente que volvía inválido todo matrimonio entre cristianos y no cristianos. Desde los primeros tiempos, con los escritos del apóstol Pablo, se planteó la inconveniencia de este tipo de uniones y varios concilios altomedievales las condenaron. En el s. XII, a partir de la reinterpretación de las prescripciones veterotestamentarias que prohibían a los judíos tomar mujeres extranjeras, se establecerá la ilicitud de los matrimonios mixtos y se declarará su nulidad total en función de su invalidez. Para que el matrimonio comunique el sacramento a los cónyuges era requisito indispensable que ambos estuviesen bautizados y es en este sentido que la disparitas cultus era un impedimento dirimente respecto de la causa final del matrimonio desde el momento en que (al igual que la impotencia) bloqueaba la finalidad de la generación de prole para el culto de Dios. La diferencia religiosa sí podía contemplarse en el caso de esponsales de palabras de futuro siempre que incluyeran la promesa de conversión al cristianismo del esposo infiel antes de los votos de palabras de presente y ello pese a la reticencia canónica a aceptar matrimonios condicionados.

La prohibición de matrimonios mixtos se entiende, pues, en función de esta lógica sacramental, aunque también se vincula con la batería de medidas que desde tiempos tempranos buscaba evitar cualquier intimidad con infieles que pusiera en riesgo la pureza de fe de los cristianos y más aún si tal intimidad suponía el ejercicio de un poder por parte del no cristiano (no solo el poder marital sino también el que se ejerce sobre la servidumbre $)^{11}$. Muchos autores han destacado el cariz sexual de esta intimidad que se proscribe más allá del lazo matrimonial. En efecto, existe una continua intención de evitar cualquier tipo de contacto carnal entre cristianos e infieles, en particular cuando se trata de judíos, preocupación que se tiñe a veces del discurso de la impureza y que ha permitido a varios historiadores plantear un punto de inflexión en la historia del tradicional antijudaísmo medieval, incluyendo para la Baja Edad Media unas valencias no estrictamente raciales pero sí con cierto tinte biológico o corporal ${ }^{12}$. James Brundage ha planteado que la prohibición de relaciones maritales o sexuales excedía al temor de una eventual apostasía y que debía pensarse como un tabú ligado a la necesidad de pureza ritual ${ }^{13}$. David Nirenberg, por su parte, destacó la simbólica de parentesco del honor de un Dios cristiano que, actuando como un paterfamilias, proscribía las relaciones sexuales interconfesionales a partir de la sexualización de la Iglesia, concebida como n o -

${ }^{11}$ La prohibición teodosiana (C. 1, 9, 18) que buscaba evitar a todo cristiano quedar bajo potestad de un judío fue reforzada en el contexto del IV Concilio Laterano. Véase QUAGLIONI, Diego, "Christianis infesti". Una mitologia giuridica dell'età intermedia: l'ebreo come "nemico interno", en Quaderni Fiorentini per la Storia del Pensiero Giuridico Moderno, 38 (2009), pp. 201-224, p. 218.

${ }^{12}$ Véase Boureau, Alain, L'Evénement sans fin. Recit et christianisme au Moyen Age (Paris, Les Belles Lettres, 1993), pp. 220-221; Iogna-Prat, Dominique, Pode-se falar de anti-semitismo medieval?, en Signum, 4 (2002), p. 83 ss.

${ }^{13}$ Brundage, James, Intermarriage between Christians and Jews in Medieval Canon Law, en Jewish History, 3/1 (1988), pp. 25-40. Sobre la asimilación del contacto carnal i n t e r r e l i g i o s o con el crimen de bestialismo, véase MAZZANTI, Giuseppe, "Habere rem cum iudea a christiano est rem habere cum cane iuris interpretation". La "damnata commixtio" e il reato di bestialità nella dottrina giuridica di diritto comune, en Historia et ius, 11 (2017), pp. 1-14. 
vi a d e C r is t o ${ }^{14}$. Este tipo de fobia de contacto sexual es por momentos explícita en el discurso eclesiástico tal como lo señala la fundamentación que el IV Concilio de Letrán de 1215 (c. 68) esgrime respecto del uso obligatorio de vestimentas y signos distintivos para los infieles que viven en tierras cristianas pues acaece que "por error" muchas veces se unen hombres y mujeres de distinta ley: "Vnde contingit interdum quod per errorem christiani Iuderoum seu Saracenorum et Iudei seu Saraceni christianorum mulieribus commiscentur" 15 .

Un ejemplo de la gravedad de estas uniones nos lo ofrece un consilium de dudosa atribución a Oldrado de Ponte (c. 333) que trata sobre el castigo a un "Iudeus cognoscens carnaliter Christianam"16. Tras recordar que las uniones matrimoniales entre cristianos y judíos están prohibidas porque el matrimonio implica una comunicación sancionada por la ley divina ("quia cum matrimonium sit communicatio divini iuris”) y tras señalar que en el caso en cuestión el acusado no intentó disfrazar con un falso matrimonio su acceso carnal ni incluyó otras faltas graves como el rapto, la violación o el incesto, el jurista propone evitar la severidad aunque concuerda en que tal "feda commixtio" no podía permanecer impune. Sin embargo, el final del consilium es elocuente: "Ego Oldradus predicta scripsi et sigillum apposui. Sed Dominus $R$. de Apulea, et Dominus Ant. de Cruce, qui tunc preerant in officio iudicatus Avinion., dictum Iudeum in amissione virilium condemnaverunt, cuius nomen erat Pandonus, et ego vidi virilia incisa ante palatium".

Ahora bien, los análisis que insisten en la fobia de contacto sexual con infieles más allá de la celebración de cualquier lazo matrimonial (por otro lado prohibidos) pecan de cierto anacronismo al distinguir entre lazos parentales y relaciones sexuales, diferenciación de sentido común en la sociedad contemporánea pero que no se corresponde con los ordenamientos jurídicos del mundo bajomedieval. En efecto, de acuerdo con la legislación canónica, las relaciones parentales de afinidad (que complementan a las de consanguinidad) no se derivan estrictamente del vínculo conyugal sino de cualquier coito, "quemlibet coitum ordinatum"17, vale decir, cualquier ayuntamiento carnal efectivo y acorde con la naturaleza que suponga el contacto de sangres pues es en esos términos como se piensa la unitas

\footnotetext{
${ }^{14}$ Nirenberg, David Conversion, sex and segregation, en American Historical Review, (octubre 2002), pp. 1066-1078; KarRas, Ruth Mazo, Unmarriages. Women, Men, and Sexual Unions in the Middle Ages (Philadelphia, University of Pennsylvania Press, 2012), pp. 108-114.

${ }^{15}$ García y García, Antonio, Constitutiones Concilii quarti Lateranensis una cum Commentariis glossatorum (Città del Vaticano, 1981), p. 107.

${ }^{16}$ Zacour, Norman, Jews and Saracens in the Consilia of Oldradus de Ponte (Toronto, Pontifical Institute of Mediaeval Studies, Studies and. Texts, 100, 1990), p. 90.

${ }^{17}$ En Summa de Esteban de Tournai, ad C. 35, q. 2-3, Esteban de Tournal, Die summa über das Decretum Gratiani (J.F. von Schulte [ed.], Giesen, 1891; reimp. Aalen: Scientia, 1965). En Partidas IV, 6 de Alfonso X podemos ver una definición de la afinidad: "Affinidad, segund derecho canonico, es proximidad de personas, proueniente de ayuntamiento carnal, careciente de toda parentela. E es assi dicha affinidad, casi unidad de dos a un fin, porque dos diuersas cognaciones se copulan en ella, o por desposorio, segund leyes, o por coyto, segund canones". Las citas de Partidas siguen la edición de Gregorio López: Las Siete Partidas (Salamanca, Andrea de Portonaris, 1555, reimp. Madrid, Boletín Oficial del Estado, 1974).
} 
carnis $^{18}$. Por lo tanto, las relaciones sexuales extramatrimoniales generan también afinidad y por ello nuestro infortunado acusado del consilium de Oldrado, aun si no se había casado ni hubiera podido hacerlo, había entrado sin embargo en una red de parentesco que le estaba vedada ${ }^{19}$.

Fuera entonces porque el impedimento disparitatis cultus volvía nulo todo matrimonio, fuera porque toda relación sexual entre cristianos e infieles estaba en última instancia prohibida, todo da a entender que no hay lugar posible para hablar de ruptura del vínculo conyugal por diferencia religiosa en el mundo bajomedieval. Sin embargo, hay dos situaciones planteadas tanto a nivel teórico como práctico que vuelven necesarios ciertos desarrollos jurídicos y la toma de algunas decisiones normativas.

El primer escenario viene dado por la hipótesis de un matrimonio de infieles en el que uno solo de los cónyuges se convierte al cristianismo. Esta situación plantea una serie de interrogantes sucesivos. En primer lugar, ¿cómo se conceptualiza el matrimonio hecho en la vieja ley en el caso de conversión de uno o de ambos cónyuges? Luego, si se lo considera legítimo, ¿se lo ha de mantener en la nueva ley con sus respectivas obligaciones y en tal caso bajo qué modalidades dadas las radicales diferencias entre las normativas matrimoniales de las diferentes leys? En el caso de conversión de uno solo de los cónyuges y dado que la legislación prohíbe las uniones mixtas, ¿se debe habilitar la posibilidad de un divorcio? Y si se responde afirmativamente a esta pregunta, por último, ¿ello incluye la posibilidad de contraer nuevo matrimonio? ${ }^{20}$.

Respecto de los matrimonios efectuados bajo otra ley, la lógica de pluralidad de órdenes normativos invitaba a considerarlos legítimos siempre y cuando éstos respetaran el derecho natural y el divino, aun por fuera de la jurisdicción eclesiástica. La existencia de una mutua fides y de una prole además de la función básica de remedio a la concupiscencia parecían elementos suficientes para suponerlos legítimos. Podemos vislumbrar claramente que, por detrás de las inferencias lógicas, también operaba una mentalidad práctica que identificaba en una eventual posición rigorista un fuerte obstáculo a la conversión de los infieles que habrían visto, tras abrazar la nueva fe, a sus hijos convertidos en bastardos y a sus esposas en concubinas. Desde esta perspectiva, se comprende la repetición de sentencias como la de Ambrosio acerca de que el bautismo lava pecados pero no anula matrimonios que, por ejemplo, parafrasea el Decreto de Graciano en C. 28, q. 2, c. 1 ('Crimina enim in baptismo soluuntur, non coniugia') ${ }^{21}$.

La calificación de matrimonio legítimo que tenía aquel realizado bajo otra ley

${ }^{18}$ Véase EsmeIn, Adhémar, Le mariage en droit canonique (Paris, Larose et Forcel, 1891), pp. 377-379; GAUDEMET, Jean, Indissolubilité et consommation du mariage. L'apport d'Hincmar de Reims, en Revue de Droit Canonique, 30 (1980), pp. 28-40.

${ }^{19} \mathrm{Si}$ bien la prohibición de matrimonio i n t e r r e l i g i o s o es temprana (388), la proscripción de todo contacto sexual es de origen bajomedieval. Cfr. Mazzanti, Giuseppe, cit. (n. 13), p. 1.

${ }^{20}$ Véase SWIACZNY, Seweryn La disolución del vínculo en el matrimonio de los no bautizados: ejercicio de la potestad pontificia, en Cuadernos doctorales, 16 (1999), pp. 66-125.

${ }^{21}$ Graciano, Corpus Iuris Canonici (Friedberg, E. [ed.], Graz, Akademische Druck. u. Verlagsanstalt, 1958). 
no ahorró dificultades a la hora de aceptar la continuidad de tal unión una vez que los cónyuges infieles se hicieran cristianos. Las normativas podían ser tan disímiles que las posibilidades prácticas de preservar dichas uniones eran muy reducidas. Tres cuestiones surgieron recurrentemente: qué hacer con un matrimonio polígamo (como el de los musulmanes), cómo aceptar un matrimonio reñido con las normas cristianas del incesto (como el levirato judío), qué reglas establecer en el caso de repudios hechos según las normas previas. Para cada hipótesis se idearon respuestas distintas pero la tónica general fue la de la dispensa y la aceptación ${ }^{22}$.

Ahora, el caso donde uno solo de los cónyuges infieles se hacía cristiano era el más controvertido pues lo que hasta entonces era un matrimonio legítimo se convertía tras el bienvenido acto de la conversión en una unión mixta, por lo tanto, en una unión inválida por el impedimento de la disparidad de cultos. Aquí entra a jugar un texto de máxima autoridad, las palabras del apóstol Pablo en I Cor. 7, 12-16, lo que se llamará el privilegio paulino que establecía que si un cristiano tenía un cónyuge no creyente, si este último quería continuar la cohabitación, se mantenía la unión pero en caso contrario el creyente quedaba libre de toda obligación. La conceptualización que finalmente triunfará y que permitirá combinar esta posibilidad de divorcio con la legitimidad de la unión a disolver será la que se centre en la naturaleza no sacramental de los matrimonios realizados bajo otra ley. Vemos una explicación en Partidas IV, 10, 4 que retoma las decisiones canónicas comparando los casamientos en uno y otro mundo: mientras en el "casamiento que es fecho derechamente entre los christianos" se cumplen tres requisitos, "comienço e afirmança, e acabamiento" (initiatum, ratum, consummatum), los casamientos "de las otras leyes" carecen de "firmança" lo que habilita que avenga "departimiento". En el casamiento hecho bajo otra ley no interviene la gracia ni se efectúa la unión de Cristo y la Iglesia; no es un matrimonio firme y por ello se habilita un divorcio total si se cumple la cláusula de la contumelia Creatoris que vemos descripta en otra ley de Partidas (IV, 10, 3): "Contumelia Creatoris, que quiere tanto dezir, como denuesto de dios, e de la nuestra fe, es en manera de fornicio spiritual: porque podria acaescer, que seria fecho diuorcio entre algunos que estouiessen casados. E esto seria, como si algunos que fuessen moros, o judios seyendo ya casados segund su ley, se fiziesse alguno dellos christiano; e el otro queriendo fincar en su ley non quisiere morar conel o si quisiesse morar conel, denostasse, antel muchas vezes a dios, e a nuestra fe: O se trauasse conel cada dia, que dexasse la fe delos christianos, e se tornasse a aquella que auia dexado. Ca por qualquier destas tres razones el christiano, o la christiana: puede se partir del otro, non demandando licencia a ninguno: e puede casar con otro, o con otra, si quisiere".

En este marco, un interesante punto de debate surge en torno de si el tratamiento ha de ser el mismo o diferenciado de acuerdo con la ley de origen del

${ }^{22}$ Cfr. por ejemplo Partidas IV, 6, 6: "Mas si algunos seyendo moros, o judios casando segund su ley seyendo parientes, o cuñados: e despues desto se tornassen christianos: algunos de aquellos que assi fuessen casados: non deue ser desfecho el casamiento por esta razon maguer que sean parientes o cuñados fasta el quarto grado. Esto otorgo santa eglesia por honrra, e por acrecentamiento dela fe: por que los que non fuessen de nuestra ley, non les embargasse de se tornar christianos, el pesar que aurian de se partir de sus mujeres: con quien estouiessen casados segund su ley". 
converso, particularmente en el caso del judaísmo. En la Summa de matrimonio de Tancredo se da cuenta de esta posición, en principio superada para entonces por las decisiones canónicas que imponían igualdad de trato: "Nec est recipienda illa distinctio, quod aliud sit in Judaeis conversis, et aliud in paganis. Quia quidam dixerunt, quod Judaeus conversus ad fidem non debet cohabitare uxori infideli volenti cohabitare, sed Sarrcenus, vel paganus conversus poterunt cohabitare: quoniam idem juris est hodie in utrique" 23 .

Esa postura contraria con su fundamentación la podemos encontrar en otro texto alfonsí, Espéculo 5, 8, 35, que compara judíos y musulmanes respecto de las capacidades en uno y otro caso de provocar en el cónyuge converso una recaída en la infidelidad: "E por ende dezimos, que aquello que dize en la ley ante desta que pueden morar en vno marido e mugier, maguer ssean de ssennas leys, que esto sse entiende de los moros et de los gentiles, mas non de los judios; ca los moros et los gentiles, comoquier que ayan ssus creençias apartadas de nos, non an ffirmedunbre de ley que sse pueda prouar por proffectas njn por ssantos. Et por ende quando la mugier o el marido ffuese de vna destas ssectas, et el otro cristiano, non deuen ante auer ssospecha que los tornassen a las ssus creençias que ante aujen, pues que non an rrazones tan ffirmes por que lo puedan ffazer. Et por ende non los deuen partir ssi non en la manera que dixiemos en esta otra ley. Mas los judios que an la Vieja Ley que creemos que dio Dios a Moyssen, et es prouado por muchas proffectas et por muchos ssantos, et es la ssu ley comjenço e testimonjo de la nuestra; por este ayuntamjento que a la ssu ley con la nuestra, sserie ssospecha que los que sse conuertiessen a la nuestra Ley et quissiessen ffincar en el casamjento primero con los de la ssuya, que punnarien de los engannar, et de los tornar a la ssu creençia et ssacar los de la nuestra. Et, demas, dezimos avn que ssi el que ffuese de nuestra Ley quissiesse conuertir al judio, que non lo podrie ffazer tan ayna como al moro o al gentil. Et por ende ssi alguno de la ley de los judios, varón o mugier, sse tornare a la nuestra Ffe et ffuer casado, tenemos por bien que el perlado daquel lugar amoneste al que ffincare en la ley de los judios que sse torne cristiano. Et ssi non lo quissiere ffazer, que dalli adelante que los departa"24.

El trasfondo de este tipo de comparaciones reside en el profundo desprecio que el islam genera como fe entre los cristianos frente al indudable (y odioso) parentesco que implica el judaísmo como también en un creciente antijudaísmo que lleva por ejemplo a decir que la Virgen (según Cantigas de Alfonso X, 348)

${ }^{23}$ Tancredo, Summa de matrimonio (A. Wunderlich [ed.], Gottingen, Vandenhocke \& Ruprecht, 1841), p. 45. Cfr. también la Summa de Raimundo de Peñafort: "\& licet quídam distinxerint, dicentes, aliud esse Judaeis, aliud in Paganis conversis; quia Judaeus conversus ad Fidem non debet cohabitare uxori infideli nolenti cohabitare sed Sarracenus conversus potest. Videtur hodie idem judicium in utriusque", RaImundo DE Peñafort, Summa Sancti Raymundi de Peniafort [...] cum glossis Joannis de Friburgo (Avignon, Mallard, Delorme \& Chastanier, 1715), p. 800.

${ }^{24}$ Alfonso X, Espéculo (R. MacDonald [ed.], Madison, Universidad de Richmond, 1990). La ley correspondiente a este punto en Partidas $(4,10,3)$ no hace diferencia alguna entre judíos y musulmanes. Opinión similar a la del pasaje citado del Espéculo hallamos en la Summa de matrimonio de Roberto de Flamesbury: "In solis Judeis aliter est, quia, quicquid sit, neuter reliquum potest retinere, nisi ambo convertantur. Solutum est ergo matrimonium, licet quidem dicant, quod non et male, ut videtur, quia sic cogeretur quis invitus continere", ROBERTI FLAMESBURIENSIS, Summa de matrimonio et de usuris (J.F. Schulte [ed.], Glessen, 1868), p. XVII. 
considera a los "judeos, seus êemigos, a que quer peor ca mouros" 25 o al ya citado Oldrado da Ponte a argumentar, respecto del caso de un judío que se convierte al islam (consilium 51) que la secta de los sarracenos no es tan mala como la judía y por lo tanto no debe ser castigado quien elige un mal menor ${ }^{26}$.

\section{MATRIMONIO Y HEREJÍA}

Hasta aquí el primer escenario. El segundo es su espejo invertido, es decir, uno cuyo punto de partida es un matrimonio cristiano y donde uno de los cónyuges apostata o cae en la herejía. Pero previamente debió precisarse en la doctrina clásica si el impedimento disparis cultus alcanzaba también a las uniones entre cristianos ortodoxos y herejes. Durante siglos, las sucesivas condenas a los matrimonios mixtos no hicieron diferencia específica entre infieles y herejes. Pero en el s. XII, con la labor de Huguccio a la cabeza, se planteará un doble régimen. A diferencia del caso de uniones con infieles cuyo tratamiento ya vimos, se postuló que todo matrimonio con herejes estaba prohibido a los buenos cristianos pero al mismo tiempo se reconocía la validez de aquellas uniones ya contraídas. Es decir, un cristiano ortodoxo que se casa con un hereje puede ser sancionado por ello pero su matrimonio, en tanto se efectuó entre personas bautizadas, tendrá naturaleza sacramental y por lo tanto no podrá ser disuelto. En palabras de Huguccio: "Dico quod, hic prohibetur ne contrahatur cum talibus, set non dicitur hic quod debeat separari si contractum fuerit. Item non dicitur quod non sit matrimonium inter tales et tales, sed dicitur quod non debeat contrahi cum talibus" 27 .

Desde Huguccio se señala, entonces, un doble impedimento disparis cultus para la celebración de matrimonios pero no quedaba fijado el procedimiento en la hipótesis, cada vez más frecuente en la época, de una caída en la herejía o un abandono de la fe posteriores a la consumación del vínculo. ¿Era posible aplicar el privilegio paulino a estos matrimonios con herejes que, por otra parte, eran excomulgados ipso iure y nadie debía comunicar con ellos? ¿Podía sobrevivir el lazo sacramental con este tipo de defecciones calificadas de for n i c a c i ó n e s p i r i t u a l y donde parecía mayor la contumelia Creatoris? Lo cierto es que la normativa no era clara y el propio Huguccio, en su calidad de obispo de Ferrara, le planteó la duda al pontífice Inocencio III pues la legislación de antecesores de este papa parecía habilitar un divorcio total con posibilidad de nuevo casamiento en este tipo de casos, como en la decretal Laudabilem de Celestino III. La respuesta

${ }^{25}$ BagBY, Albert, Alfonso X, el Sabio, compara moros y judios, en Romanische Forschung, 82 (1970), pp. 578-583.

26 "Imo cum secta Saracenorum sit minus mala quam Judaeorum [...] Non est ergo puniendus qui viam minus malam elegit". También ver BRUndaGe, James, cit. (n. 13), p. 28. Sobre la desigual conceptualización del judaísmo y el islam, ver Morin, Alejandro, Pecado y delito en la Edad Media. Estudio de una relación a partir de la obra jurídica de Alfonso el Sabio (Córdoba, Ordia Prima, 2009), pp. 170-179.

${ }^{27}$ Cantelar Rodríguez, Francisco, El matrimonio de herejes. Bifurcación del “impedimentum disparis cultus" y divorcio por herejía (Salamanca, CSIC, 1972) p. 102; DieHL, Peter, Heresy as grounds for divorce, en Proceedings of the Ninth International Congress of Medieval Canon Law Munich, 1992 (Città del Vaticano, 1997), p. 981. 
vendrá dada por la decretal Quanto te, incorporada luego al Liber Extra: "Si vero alter fidelium coniugum, vel labatur in haeresim, vel transeat ad gentilitatis errorem, non credimus, quod in hoc casu, is qui relinquitur, viuente altero possit ad secundas nuptias convolare, licet in hoc casu maior appareat contumelia creatoris. Nam etsi matrimonium verum quidem inter infideles exsistat, non tamen est ratum: inter fideles autem verum et ratum existit: quia sacramentum fidei quod semel est admissum, numquam amittitur, sed ratum efficit coniugii sacramentum, ut ipsum in coniugibus illo durante perduret" 28 .

La respuesta de Inocencio zanja, en principio, la cuestión planteando la indisolubilidad del vínculo matrimonial entre cristianos aun si sobreviene la caída en herejía o la apostasía de uno de los cónyuges. En todo caso, y para evitar el contagio del mal y asegurar el aislamiento propio de los excomulgados, se puede prescribir un divortium quoad torum, una separación de los esposos pero sin posibilidad de nuevo matrimonio hasta que la muerte de uno de ellos libere del vínculo al otro. Sin embargo, la decisión legislativa de Inocencio III no eliminará las dudas y, tal como plantea Peter Diehl, las continuas demandas de divorcio por herejía bastante después de la promulgación de la decretal Quanto te indican la persistencia de un sentimiento generalizado de que herejía y apostasía efectivamente disolvían el vínculo como lo haría la muerte ${ }^{29}$.

Pero así como con el matrimonio de infieles la postura tiende al laxismo para promover la conversión, en el caso de matrimonios cristianos la política oficial es rotundamente rigorista haciendo prevalecer la indisolubilidad matrimonial por encima de las medidas de persecución antiherética. Así lo podemos ver con algunos ejemplos. En la propia decretal Quanto te de Inocencio se prevé la hipótesis de una simulación de la herejía como forma de lograr una ruptura total, posibilidad que se bloquea allí de forma explícita pues se establece que el matrimonio tiene más fuerza: "Per hanc autem responsionem quorundam malitiae obviatur, qui in odium coniugum, vel quando sibi invicem displicerent, si eas possent in tali casu dimittere, simularent haeresim, ut ab ipsa nubentibus coniugibus resilirent" ${ }^{30}$. La misma decretal incluso regula la obligación del cónyuge fiel de retomar la cohabitación en caso de arrepentimiento del esposo descreído ${ }^{31}$ (rasgo que diferencia el régimen de la for n i c a c i ó n e s p i r i t u a l de la simple fornicación que permite iniciar acciones por divortium quoad torum incluso después del arrepentimiento del cónyuge adúltero ${ }^{32}$ ). Por último, una quaestio de Roffredo de Benevento en torno de un caso de demanda de divorcio y repetición de dote que hace una mujer respecto de su esposo excomulgado tiempo ha. Roffredo, jurista de la corte de Federico II,

${ }^{28}$ Véase Dauvillier, Jean, cit. (n. 8), p. 183; Esmein, Adhémar. cit. (n. 18), p. 231; CANTERAL Rodríguez, Francisco, cit. (n. 27), pp. 167 ss.; DieHL, Peter cit. (n. 27), p. 987.

${ }^{29}$ DieHL, Peter, cit. (n. 27), pp. 975-996.

${ }^{30}$ X IV, 19, 7, en Corpus Iuris Canonici, cit. (n. 21).

31 "Per hanc ipsam responsionem illa solvitur quaestio, qua quaeritur, utrum ad eum, qui ab haeresi vel infidelitate revertitur, is, qui permansit in fide, redire cogatur".

${ }^{32}$ Sobre la figura de la fornicación espiritual en Partidas y la acción de divorcio fundada en ella, ver Martínez Marcos, Esteban, Las causas matrimoniales en las Partidas de Alfonso el Sabio (Salamanca, C.S.I.C., 1966), pp. 102-103. 
tras acordar que la excomunión puede ser equiparada a la muerte civil, niega la repetición de dote apelando a la unidad de carne y la indisolubilidad del vínculo: "Praeterea a dotem non repetes: ideo quia \& tu mulier, excommunicata es: sunt enim una caro maritus \& mulier, unde si ego sum excommunicatus, ergo \& tu: nam it est inseparabile nostrum vinculum, quod nulla de causa separetur: nam quod dominus iunxit, homo non separet" ${ }^{\prime 3}$. Y luego asevera, en primer lugar, que, de dar cabida al divorcio por excomunión, se abriría la compuerta a muchos otros y se pondría en riesgo la procreación ("Item si hoc esset multa matrimonia dissoluerentur: \& sic liberi non procrearentur: \& ciuitas liberis non repleretur"), y en segundo lugar que, si está mal cohabitar con un excomulgado, peor es la deserción y hay que elegir el mal menor: "Item malum est sicut dicis uxorem cohabitare viro excommunicato : deterius tamen esset si ab eo separaretur: unde de his duobus malis minus malum est eligendum".

Vemos entonces que en la legislación que aborda el lazo conyugal entre cristianos ortodoxos e infieles o herejes, la formulación radical del matrimonio cristiano prevalece por encima de figuras como la disparitas cultus o la fornicación espiritual. Se cruzan en esta temática intereses diversos que dan lugar a políticas eventualmente contrapuestas: la promoción de la conversión de infieles al cristianismo, la búsqueda de aislamiento social de los herejes, la preservación a ultranza del vínculo conyugal cristiano en los términos en que se construyó desde el s. XII. En este marco, apreciamos que la ficción de la unitas carnis revela en situación una fuerza operativa mayor que otras, como es el caso de la ficción de la muerte civil: un hereje excomulgado es para el derecho un muerto en vida pero manifiesta una vitalidad suficiente como para poder sostener relaciones maritales en regla.

BiBLIOGRAFÍA

Alfonso X, Espéculo (R. MacDonald [ed.], Madison, Universidad de Richmond, 1990).

Alfonso X, Las Siete Partidas (Salamanca, Andrea de Portonaris, 1555, reimp. Madrid, Boletín Oficial del Estado, 1974).

ÁlvareZ de las Asturias, Nicolás, La formación del vínculo matrimonial de Graciano a Alejandro III: ¿tan sólo una cuestión histórica?, en Ius Canonicum, 53 (2013), pp. 621-654.

Bagby, Albert, Alfonso X, el Sabio, compara moros y judios, en Romanische Forschung, 82 (1970), pp. 578-583.

Borgmann, Brigitte, Mors civilis: die Bildung des Begriffs im Mittelalter und sein Fortleben im französchen Recht der Neuzeit, en Ius commune, 4 (1972), pp. 81-157.

\footnotetext{
${ }^{33}$ Roffredo Da Benevento, Sabbatinae Quaestiones, en Tractatus in quo ordinis iudiciarij positiones libellique pertractantur (Lyon, apud haeredes Iacobi Iuntae, 1561), pp. 709. Véase Vodola, Elizabeth, Excomminication in the Middle Ages (Berkeley, University of California Press, 1986), p. 65. Sobre la figura en construcción para el derecho bajomedieval de la muerte civil, véase BORGMANN, Brigitte, Mors civilis: die Bildung des Begriffs im Mittelalter und sein Fortleben im französchen Recht der Neuzeit, en Ius commune, 4 (1972), pp. 81-157.
} 
Boureau, Alain, L'Evénement sans fin. Recit et christianisme au Moyen Age (Paris, Les Belles Lettres, 1993).

BRUNDAGE, James, Intermarriage between Christians and Jews in Medieval Canon Law, en Jewish History, 3/1 (1988), pp. 25-40.

Brundage, James, La ley, el sexo y la sociedad cristiana en la Europa medieval, (trad. cast., México, F.C.E. 2000).

Cantelar Rodríguez, Francisco, El matrimonio de herejes. Bifurcación del impedimentum disparis cultus y divorcio por herejia (Salamanca, CSIC, 1972).

Dauvillier, Jean, Le mariage dans le droit classique de l'Église, depuis le Décret de Graden (1140) jusqu'à la mort de Clément V (1314) (Paris, Recueil Sirey, 1933).

Dienl, Peter, Heresy as grounds for divorce, en Proceedings of the Ninth International Congress of Medieval Canon Law Munich, 1992 (Città del Vaticano, 1997).

Dillard, Heath, Daughters of the Reconquest. Women in Castilian Town Society, 11001300 (Cambridge, University Press, 1984).

DuBy, Georges, Le chevalier, la femme et le pretre. Le mariage dans la France féodale (Paris, Hachette, 1981).

EsMeIn, Adhémar, Le mariage en droit canonique (Paris, Larose et Forcel, 1891).

Esteban de Tournai, Die summa über das Decretum Gratiani (J.F. von Schulte [ed.], Giesen, 1891; reimp. Aalen: Scientia, 1965).

FriedberG, Emil (ed.), Corpus Iuris Canonici (Graz, Akademische Druck. u. Verlagsanstalt, 1958).

García y García, Antonio, Constitutiones Concilii quarti Lateranensis una cum Commentariis glossatorum (Città del Vaticano, 1981).

GaUdemet, Jean Indissolubilité et consommation du mariage. L'apport d'Hincmar de Reims, en Revue de Droit Canonique, 30 (1980), pp. 28-40.

Le Mariage en Occident. Les moeurs et le droit (Paris, Les Editions du Cerf, 1987).

Guerreau, Alain El feudalismo. Un horizonte teórico (trad. cast. Barcelona, Crítica, 1984).

Guerreau-Jalabert, Anita, El sistema de parentesco medieval. Sus formas (reall espiritual) y su dependencia con respecto a la organización del espacio, en PASTOR, Reyna (comp.), Relaciones de poder, de producción y parentesco en la Edad Media y Moderna. Aproximación a su estudio (Madrid, Consejo Superior de Investigaciones Científicas, 1990).

Iogna-Prat, Dominique, Pode-se falar de anti-semitismo medieval?, en Signum, 4 (2002).

Karras, Ruth Mazo, Unmarriages. Women, Men, and Sexual Unions in the Middle Ages (Philadelphia, University of Pennsylvania Press, 2012).

Madero, Marta, La loi de la chair. Le droit au corps du conjoint dans l'euvre des canonistes (XIIe-XVe siècles) (Paris, Publications de la Sorbonne, 2015).

Martínez Marcos, Esteban, Las causas matrimoniales en las Partidas de Alfonso el Sabio (Salamanca, C.S.I.C., 1966).

Mayal, Laurent, "Duo erunt in carne una" and the Medieval Canonists, en Colli, Vincenzo y ConTe, Emanuele (eds.), Iuris Historia: Liber Amicorum Gero Dolezalek (Berkeley, The Robbins Collection, 2008), pp. 161-75.

MaZZANTI, Giuseppe, "Habere rem cum iudea a christiano est rem habere cum cane iuris interpretatione". La "damnata commixtio" e il reato di bestialità nella dottrina giuridica di diritto comune, en Historia et ius, 11 (2017), pp. 1-14. 
Morin, Alejandro, Pecado y delito en la Edad Media. Estudio de una relación a partir de la obra jurídica de Alfonso el Sabio (Córdoba, Ordia Prima, 2009).

Morsel, Joseph, L'Histoire (du Moyen Âge) est un sport de combat (Paris, Lamop-Paris I, 2007).

Nirenberg, David Conversion, sex and segregation, en American Historical Review, (octubre, 2002), pp. 1066-1078.

Owen Hughes, Diane Il matrimonio nell'Italia medievale, en Klapisch-Zuber, Christiane \& De Giorgio, Michela, Storia del matrimonio (Bari, Laterza, 1996).

Quaglioni, Diego, "Christianis infesti”. Una mitologia giuridica dell'età intermedia: l'ebreo come "nemico interno", en Quaderni Fiorentini per la Storia del Pensiero Giuridico Moderno, 38 (2009), pp. 201-224.

Raimundo de Peñafort, Summa Sancti Raymundi de Peniafort [...] cum glossis Joannis de Friburgo (Avignon, Mallard, Delorme \& Chastanier, 1715).

Reynolds, Philip L., The Regional Origins of Theories about Marital Consent and Consummation during the Twelfth Century, en Korpiola, Mia, Regional Variations in Matrimonial Law and Custom in Europe, 1150-1600 (Leiden, Brill, 2011), pp. 43-75.

Roberti Flamesburiensis, Summa de matrimonio et de usuris (J.F. Schulte [ed.], Glessen, 1868).

Roffredo da Benevento, Sabbatinae Quaestiones, en Tractatus in quo ordinis iudiciarij positiones libellique pertractantur (Lyon, apud haeredes Iacobi Iuntae, 1561).

Rolando, Die Summa Magistri Rolandi nachmals Papstes Alexander III (F. Thaner [ed.], Innsbruck, Verlag der Wagnerischen Universitaets-Buchhandlung, 1874).

SWIACZNY, Seweryn La disolución del vínculo en el matrimonio de los no bautizados: ejercicio de la potestad pontificia, en Cuadernos doctorales, 16 (1999), pp. 66-125.

TANCREDO, Summa de matrimonio (A. Wunderlich [ed.], Gottingen, Vandenhocke \& Ruprecht, 1841).

Vallejo, Jesús, Derecho como cultura. Equidady orden desde la óptica del "ius commune", en De Dios, Salustiano et al. (coords.), Historia de la propiedad. patrimonio cultural, III: Encuentro interdisciplinar, Salamanca, 28-31 de mayo de 2002 (Madrid, Servicio de Estudios del Colegio de Registradores, 2003).

Vodola, Elizabeth, Excomminication in the Middle Ages (Berkeley, University of California Press, 1986).

Zacour, Norman, Jews and Saracens in the Consilia of Oldradus de Ponte (Toronto, Pontifical Institute of Mediaeval Studies, Studies and. Texts, 100, 1990). 